\title{
Alemtuzumab as Treatment for Multiple Sclerosis
}

\author{
Serafeim Katsavos and Alasdair Coles \\ Department of Clinical Neurosciences, University of Cambridge, Cambridge Biomedical Campus, Hills Road, \\ Cambridge CB2 0QQ, United Kingdom \\ Correspondence: ajc1020@medschl.cam.ac.uk
}

\begin{abstract}
Alemtuzumab, the first monoclonal antibody to be used as a therapy and the first to be humanized, was introduced into the treatment of multiple sclerosis in 1991 after its successful use in hematology, oncology, and transplantation medicine. One phase 2 and two phase 3 trials of this lymphocyte-depleting agent have established alemtuzumab's superior efficacy to interferon $\beta$-1a over the short term (2-3 years) with greater relapse rate reduction, reduced accumulation of disability, and more frequent sustained improvement in disability. Longerterm extension studies show durable effects on slowing cerebral atrophy over 6 years and maintained low relapse rates over 10 years, despite roughly half of patients not needing further dosing. Homeostatic proliferation of residual T cells after alemtuzumab-induced lymphopenia is probably responsible for its most common side effects: secondary autoimmunity 1 or 2 years after the last infusion of alemtuzumab affecting the thyroid gland $(30 \%$ of patients), platelets $(1 \%)$, or renal glomeruli $(0.1 \%)$. With the prerequisite of patient and physician adherence to a prolonged safety-monitoring protocol, alemtuzumab offers durable high efficacy from infrequent dosing.
\end{abstract}

\begin{abstract}
A lemtuzumab was made in the Department A of Pathology in Cambridge, United Kingdom in the 1980s and so named Campath-1H. It is the first monoclonal antibody to be used therapeutically in humans and the first to be humanized by Greg Winter's technology (Waldmann and Hale 2005). It targets CD52, a small glycoprotein abundant in lymphocytes ( $\mathrm{T}$ and B), monocytes, and eosinophils but not in hematological precursor cells. The molecule's function is not known; we have not been able to replicate all of the data behind the assertion that it is present in high density on regulatory $\mathrm{T}$ cells, which act via soluble CD52's interaction
\end{abstract}

with Siglec-10 (Bandala-Sanchez et al. 2013). A single dose of alemtuzumab rapidly depletes peripheral lymphocytes and monocytes that are undetectable within minutes, but it has less effect on secondary lymphoid tissues, as evident from studies in human CD52 transgenic mouse (Hu et al. 2009).

Alemtuzumab was originally used in transplantation medicine to prevent graft versus host disease (Waldmann et al. 1984) and then in lymphoid malignancies (Hale et al. 1988). Soon after, it was tried in systemic vasculitis (Lockwood et al. 1993). It was first used in seven patients with secondary progressive multiple sclerosis

Editors: Howard L. Weiner and Vijay K. Kuchroo

Additional Perspectives on Multiple Sclerosis available at www.perspectivesinmedicine.org

Copyright (C) 2018 Cold Spring Harbor Laboratory Press; all rights reserved; doi: 10.1101/cshperspect.a032029

Cite this article as Cold Spring Harb Perspect Med 2018;8:a032029 
(MS) in 1991 (Moreau et al. 1994) and then in a group of 29 patients with established secondary progressive MS (SPMS) and significant levels of disability (Coles et al. 1999).

\section{THE RATIONALE BEHIND THE DESIGN OF THE ALEMTUZUMAB TRIALS}

The rationale for trying alemtuzumab in SPMS back in 1991 stemmed from the hypothesis that SPMS was just a result of more aggressive inflammation in comparison to the relapsing remitting disease form (RRMS). Although a single infusion of alemtuzumab (100 mg over 5 days) radically reduced relapses and new lesion formation in the magnetic resonance imaging (MRI) scans of the first 36 patients, even 7 years postadministration (Coles et al. 1999), it failed to prevent disability progression and brain atrophy (Coles et al. 2006). Retrospectively, we believe that this represents eloquent proof either that SPMS is driven by neurodegeneration and not inflammation, or that inflammation has become trapped in the central nervous system behind a closed blood-brain barrier and therefore inaccessible to alemtuzumab (Frischer et al. 2009).

At this point, the idea of "window in therapeutic opportunity" started taking shape: the realization that immunotherapies could be effective in MS only if administered at an early disease stage. This prompted the second attempt of alemtuzumab use in MS in a group of 22 RRMS patients with mean disease duration of only 2.7 years but with aggressive disease course (mean relapse rate 2.2 and mean Expanded Disability Status Scale [EDSS] 4.8). This time, the profound reduction in mean relapse rate was also accompanied by improvement of disability by a mean of 1.2 EDSS points over 2 years (Coles et al. 2006). The encouraging open-label data were further validated by one phase 2 (CAMMS223) and two phase 3 trial studies (CARE-MS1 and CARE-MS2). In these studies, all patients received two cycles of alemtuzumab: five daily infusions at baseline $(60 \mathrm{mg})$ followed at 12 months by 3 days of infusions ( $36 \mathrm{mg}$ ).

A unique feature of these trials is that patients were required to have "early" RRMS (defined as disease duration less than 3 years in
CAMMS223, and 5 and 10 years for CAREMS1 and CARE-MS2, respectively) with minimal disability (3.0 or below for CAMMS223 and CARE-MS1 participants, 5.0 or below for CARE-MS2). Alemtuzumab's efficacy was tested both as a first-line and second-line treatment; samples in CAMMS223 and CARE-MS1 consisted of treatment-naïve patients, whereas samples in CARE-MS2 consisted of patients with disease activity despite being on one of the licensed therapies at the time. The hurdle for alemtuzumab was set high; in each trial, there was an active comparator, interferon $\beta$ $1 \mathrm{a}$, and the primary outcomes were an effect on sustained disability as well as relapse rate.

Because alemtuzumab has stereotyped and universal infusion symptoms, no attempt was made to blind patients or doctors to treatment allocation. To protect the integrity of the data, an independent "blinded rater" assessed the clinical outcome measures as suggested by the American Academy of Neurology (Goodin et al. 2002); however, this design was challenged by the Food and Drug Administration (FDA) at the time of licensing.

An extension study has collected all willing patients into a long-term study of efficacy and safety of alemtuzumab, which has now reported at 10 years (CAMMS223) or 6 years (CARE MS trials). Patients in this extension were offered retreatment with alemtuzumab (3 days, $36 \mathrm{mg}$ ) if they had one clinical relapse or two new MRI lesions on annual MRI scans. Overall, some $50 \%$ of patients do not need retreatment at all over 6 years, roughly $30 \%$ need one additional cycle, and $15 \%$ need two cycles and the remainder require more (LaGanke and Trabolousee, ECTRIMS, 2016).

\section{EFFICACY OF ALEMTUZUMAB}

Alemtuzumab was shown to be more effective than interferon $\beta$-1a in all three studies as shown in Table 1. Over 2 to 3 years, alemtuzumab reduced the risk of clinical relapse compared to interferon $\beta$-1a by $69 \%$ in CAMMS223, and by $55 \%$ and $49.4 \%$ in CARE-MS1 and CARE-MS2, respectively (Coles et al. 2008, 2012a; Cohen et al. 2012). These low relapse rates have been sus- 
Alemtuzumab as Treatment for MS

Table 1. Summary of alemtuzumab's efficacy from the three commercially sponsored clinical trials

\begin{tabular}{|c|c|c|c|}
\hline Variables & $\begin{array}{c}\text { Phase } 2 \text { CAMMS223 } \\
\qquad N=333\end{array}$ & $\begin{array}{l}\text { Phase } 3 \text { CARE-MS } 1 \\
\qquad N=581\end{array}$ & $\begin{array}{c}\text { Phase } 3 \text { CARE-MS } 2 \\
\qquad N=840\end{array}$ \\
\hline Previous DMT & No & No & Yes \\
\hline Age, year mean (SD) & $32.3(8.5)$ & $33.0(8.2)$ & $35.1(8.4)$ \\
\hline EDSS score mean (SD) & $2.0(0.7)$ & $2.0(0.8)$ & $2.7(1.2)$ \\
\hline $\begin{array}{l}\text { Disease duration, year } \\
\text { median (range) }\end{array}$ & $1.3(0.1-6.3)$ & $1.7(0.1-6.0)$ & $3.7(0.2-16.9)$ \\
\hline $\begin{array}{l}\text { Relapses in past } 2 \text { years } \\
\text { mean (range) }\end{array}$ & $2.3(1-7)$ & $2.4(1-7)$ & $2.7(1-9)$ \\
\hline Pivotal results & 3-year study & 2-year study & \\
\hline Relapse rate reduction & $69 \%^{* *}$ & $55 \% * * *$ & $50 \% * * *$ \\
\hline $\begin{array}{l}\text { Annualized relapse rate } \\
\text { (alemtuzumab vs. } \\
\text { interferon [IFN]) }\end{array}$ & 0.10 vs. 0.36 & 0.18 vs. 0.39 & 0.26 vs. 0.52 \\
\hline Proportion relapse free & $77 \%$ vs. $52 \%^{* *}$ & $78 \%$ vs. $59 \%{ }^{* * *}$ & $65 \%$ vs. $47 \%^{* * *}$ \\
\hline $\begin{array}{l}\text { Sustained disability } \\
\text { confirmed at } 6 \text { months } \\
(\%)\end{array}$ & $9 \%$ vs. $26 \%^{* *}$ & $\begin{array}{l}8 \% \text { vs. } 11 \% \\
\text { Nonsignificant }\end{array}$ & $13 \%$ vs. $21 \%^{* *}$ \\
\hline $\begin{array}{l}\text { Change in mean EDSS } \\
\text { from baseline }\end{array}$ & $\begin{array}{l}\text { Improvement of } 0.39 \\
\text { compared to deterioration } \\
\text { of } 0.38 \text { on IFN- } \beta-1 \mathrm{a}^{* *}\end{array}$ & No significant change & $\begin{array}{l}\text { Improvement of } 0.17 \\
\text { compared to deterioration } \\
\text { of } 0.24 \text { on IFN- } \beta-1 \mathrm{a}^{* * *}\end{array}$ \\
\hline $\begin{array}{l}\text { Reduction in brain atrophy } \\
\text { on alemtuzumab vs. IFN }\end{array}$ & & $42 \%{ }^{* * *}$ & $24 \% *$ \\
\hline
\end{tabular}

tained for at least 6 years in the CARE MS trials (Fox and Coles, poster presentations, ECTIMS 2016) and for 10 years in the CAMMS223 trials (Selmaj, poster presentation, ECTIMS 2016).

There is good evidence that alemtuzumab reduces the risk of accumulating disability in comparison to interferon $\beta$ - 1 a. This was statistically significant in CAMMS223 and CARE-MS2 (relative reduction by $71 \%$ and $42 \%$, respectively). Although the same trend was present in CARE-MS1, statistical significance was not reached. This was because of the unexpectedly low disability accumulation rate in the interferon-treated arm.

The alemtuzumab trials are the first to record significant improvements in disability by a mean of 0.39 or 0.17 EDSS points in CAMMS223 and CARE-MS2, respectively, compared to mean deterioration of 0.38 or 0.24 EDSS points in the interferon patients. (No such differences were seen in CARE-MS1, probably because the recruits had unexpectedly benign disease.) At 6 years, $77 \%$ of the alemtuzu- mab patients in the CARE-MS2 study had unchanged or improved EDSS compared to baseline (Fox ECTRIMS 2016) and at 10 years, the mean disability of the CAMMS223 patients was unchanged from baseline (Selmaj ECTRIMS 2016). The alemtuzumab investigators have pioneered the outcome measure of "sustained improvement in disability" to capture this effect, defined as a reduction of EDSS by 1 point or more, confirmed at 6 months (Coles et al. 2012b); 43\% of alemtuzumab patients had achieved this by 6 years in CARE-MS2 (Fox ECTRIMS 2016).

There is some objective support for these observations; in a small subgroup of 20 patients, gray matter magnetization transfer ratio, which is a biomarker of remyelination, improved after treatment with alemtuzumab, unlike in 18 interferon $\beta$-treated controls (Button et al. 2013). Advanced myelin-specific imaging techniques have confirmed this result (Vavasour et al. 2015).

No doubt, disability improvement after alemtuzumab represents endogenous repair in 
patients with short disease duration after adequate disease control with a potent anti-inflammatory agent. But we have explored the possibility that alemtuzumab might actively promote "neuroprotective autoimmunity" (described below).

Alemtuzumab showed statistically significant superiority to interferon $\beta$-1a in all MRI outcomes. More specifically, with regard to (1) the number of patients with new or enlarging T2 lesions, (2) the number of patients with gadolinium-enhancing lesions, and (3) the median change in brain parenchymal fraction measure of normalized brain volume (as a marker of cerebral atrophy). The reduced rate of cerebral atrophy in comparison to interferon was maintained for at least 2 years in more than $70 \%$ of patients, despite the lack of need for retreatment with alemtuzumab.

It remains unclear whether alemtuzumab delays the transition from RRMS to SPMS. In a cohort of 87 patients treated with alemtuzumab, with mean disease duration of 3 years before treatment, only $5 \%$ fulfilled the criteria for secondary progression after a median followup of 7 years from first infusion (Tuohy et al. 2015).

\section{ALEMTUZUMAB'S SAFETY PROFILE}

\section{Infusion Reactions}

In the early days, alemtuzumab was administered without premedication. All patients developed a systemic syndrome consisting of pyrexia, nausea, headache, urticarial rash, and sometimes bradycardia and hypotension within $2 \mathrm{~h}$ of starting the infusion. Patients also experienced a transient rehearsal of neurological symptoms and signs that had been noted during previous relapses. On one occasion, reversible conduction block was captured on visually evoked potentials from an eye with a previous history of optic neuritis (Moreau et al. 1996). All of the above phenomena were self-limiting after some hours. The subsequent introduction of high dose methylprednisolone intravenously before alemtuzumab infusion has dramatically reduced these infusion-associated symptoms. In the current clinical routine, premedication also includes antihistamine and paracetamol (see Table 2).

This "cytokine release syndrome" is probably attributed to cytokines such as interleukin (IL)-6, interferon $\gamma$, and nitric oxide produced when alemtuzumab induces cross-linking activation of natural killer cells (Wing et al. 1996).

\section{Infections}

Despite initial fears, given the prolonged lymphopenia that follows alemtuzumab, infections are not a major concern except in the immediate few weeks after infusion. Mild-to-moderate respiratory and urinary tract infections are indeed more common after alemtuzumab (Coles et al. 2008, 2012a; Cohen et al. 2012) than with interferon $\beta-1 \mathrm{a}$, as shown in a pooled analysis of CARE-MS1 and CARE-MS2 trials (Havrdova et al. 2013). In the same analysis, $16 \%$ of alemtuzumab-treated patients developed herpetic infections (11.4\% herpes simplex-mainly cold sores, $4.7 \%$ herpes zoster), versus $2.8 \%$ of interferon-treated patients. Serious infections after alemtuzumab were rare in the commercially sponsored trials, specifically $2.8 \%$ versus $1.3 \%$ in the interferon-treated group (Havrdova et al. 2013). There are no isolated cases of progressive multifocal leukoencephalopathy to date.

The relative absence of significant infections may be explained by the fact that alemtuzumab does not affect cells of the innate immune system. Retention and expansion of memory T cells the first months after the infusion (see below) may also have a contribution to this. In a small study, 24 patients were found to be "immunocompetent" after alemtuzumab in that they retained immunological memory against antigens previously met, and were capable of making normal antibody responses to novel and recall antigens when challenged by vaccination (McCarthy et al. 2013).

In this same study, one patient failed to make a normal response to vaccinations given within 1 month of alemtuzumab. This does seem to be an "at-risk" period for infections. Herpetic infections happened more frequently the first month after the infusion and were adequately prevented by a month of acyclovir prophylaxis, which also 
Table 2. Practical advice on use of alemtuzumab for multiple sclerosis

\begin{tabular}{|c|c|}
\hline $\begin{array}{l}\text { Before administering } \\
\text { alemtuzumab }\end{array}$ & $\begin{array}{l}\text { Check FBC, creatinine electrolytes, TSH, HIV, HepB and C, varicella immunity } \\
\text { (and consider vaccination is not immune), and-in TB endemic areas-CXR. }\end{array}$ \\
\hline Premedication & $\begin{array}{l}1 \mathrm{~g} \text { methylprednisolone i.v. immediately before alemtuzumab on days } 1 \text { to } 3 \text { of } \\
\text { each treatment course; antihistamines and antipyretics are advised. }\end{array}$ \\
\hline Alemtuzumab dosing & $\begin{array}{l}12 \mathrm{mg} / \text { day administered by intravenous infusion (over approximately } 4 \mathrm{~h} \text { ) for two } \\
\text { treatment courses: (1) baseline course: } 12 \mathrm{mg} / \text { day for } 5 \text { consecutive days ( } 60 \mathrm{mg} \\
\text { total dose), and ( } 2 \text { ) second course ( } 12 \mathrm{months} \text { after the initial course): } 12 \mathrm{mg} / \\
\text { day for } 3 \text { days ( } 36 \mathrm{mg} \text { total dose). }\end{array}$ \\
\hline Infection prophylaxis & $\begin{array}{l}\text { Acyclovir } 200 \mathrm{mg} \text { twice a day (against herpes simplex) starting on the first day of } \\
\text { each course and continuing for } 28 \text { days; cotrimoxazole three times weekly } \\
\text { (against Listeria), starting on the first day of each course until } 28 \text { days after the } \\
\text { last infusion (see text for alternatives). }\end{array}$ \\
\hline Posttreatment monitoring & $\begin{array}{l}\text { To monitor for idiopathic thrombocytopenic purpura (ITP) (and other } \\
\text { cytopenias), full blood counts should be obtained at monthly intervals until } 48 \\
\text { months after the last infusion. During and after this time, if ITP is suspected } \\
\text { clinically, an urgent full blood count should be obtained. The SmPc also } \\
\text { recommends monthly creatinine and urinalysis with microscopy until } 48 \\
\text { months after the last infusion. A clinically significant change from baseline in } \\
\text { serum creatinine, hematuria (not explained by menstruation), and/or } \\
\text { proteinuria should prompt further evaluation for nephropathies, including a } \\
\text { referral to a specialist. (But please see text where we argue that this monitoring } \\
\text { may be unhelpful.) Thyroid function should be monitored for } 3 \text { months after } \\
\text { treatment, until } 48 \text { months following the last infusion. After this period, testing } \\
\text { should be performed based on clinical findings suggestive of thyroid } \\
\text { dysfunction. }\end{array}$ \\
\hline Pregnancy and breastfeeding & $\begin{array}{l}\text { Pregnancy: according to the Summary of Product Characteristics (SmPC), serum } \\
\text { concentrations of alemtuzumab are low or undetectable within } 30 \text { days of each } \\
\text { treatment course. Therefore, women of childbearing potential should use } \\
\text { effective contraception when receiving a course of alemtuzumab, and for } 4 \\
\text { months following each course of treatment. Breastfeeding: it is unknown } \\
\text { whether alemtuzumab is excreted in human breast milk, but it has been } \\
\text { detected in the milk of lactating mice. Therefore, women should be advised to } \\
\text { discontinue breastfeeding during each course of treatment with alemtuzumab, } \\
\text { and for } 4 \text { months following each course of treatment. }\end{array}$ \\
\hline Vaccinations & $\begin{array}{l}\text { Patients must not receive live vaccinations after alemtuzumab. It is not known } \\
\text { definitively whether alemtuzumab affects response to vaccination, but in a pilot } \\
\text { study of } 24 \text { patients, the response appeared normal (apart, perhaps, during the } \\
\text { first few months following treatment). The SmPC suggests that vaccination } \\
\text { before alemtuzumab should be considered in patients who have not completed } \\
\text { standard required vaccines, and for those who have no immunity to } \\
\text { chickenpox. Required vaccinations should be given at least } 6 \text { weeks before } \\
\text { treatment. }\end{array}$ \\
\hline
\end{tabular}

represents the current practice (see Table 2). Rare case reports of Listeria meningitis have been described in the postmarketing era (Rau et al. 2015), with a recent fatal case in the United Kingdom. Genzyme pharmacovigilance estimates $0.25 \%$ of patients have had a Listeria infection (Pharmacovigilance Group, Genzyme, pers. comm.), all within the first 4 weeks after alemtuzumab. It is likely that this arises from Listeria colonizing the bowel at the time of treatment. Recent advice from the Association of British Neurologists is to either (1) prescribe cotrimoxazole three times weekly for 1 month after alemtuzumab, or (2) eliminate Listeria from the 
bowel with 1 week of amoxicillin before alemtuzumab and ask the patient to consume a Listeria-free diet for the month afterward.

\section{Malignancy-Proliferative Disorders}

Malignancies were not found to be more frequent in patients treated with alemtuzumab in comparison to interferon $\beta$ in the three commercially sponsored trials, but these were not powered sufficiently to pick up differences in low-frequency events. Two cases of thyroid papillary carcinoma were reported in the CAREMS1 trial, one of them in the context of a known thyroid nodule before the infusion. Both cases were treated with surgery and ablation and they recovered completely without disease reappearance (Cohen et al. 2012). A third similar case was reported in CARE-MS2 (Coles et al. 2012a). It is still not fully understood whether there is a direct or indirect etiological connection of alemtuzumab with the above incidents, or if they just represent random findings because of effective monitoring bias (Berker et al. 2011).

One patient treated with alemtuzumab in a noncommercial trial in Cambridge, UK, was diagnosed with Castleman's disease, which is considered to be a prelymphomatous condition (Jones and Coles 2014). A second patient developed hemophagocytic syndrome, which is another potentially severe hematological condition attributed to uncontrolled proliferation of chronically activated but morphologically benign lymphocytes and macrophages. Although a clear mechanism cannot be described, it is possible that these proliferative disorders were in some way triggered by the previous treatment with alemtuzumab. Initially, alemtuzumab was incriminated in the death from Burkitt's lymphoma of a patient who had been in the CAMMS223 study, but her mother subsequently developed the same tumor, and a genetic cause is more likely.

\section{Secondary Autoimmunity}

It is now well recognized that secondary autoimmunity represents the most common and important side effect of treatment with alemtuzu- mab. It can happen up to 5 years after treatment with a frequency peak at 2 years. Approximately one-third of treated patients will develop autoimmune thyroid disease, predominantly Graves' disease, because of antibody production against thyroid-stimulating hormone receptors (Costelloe et al. 2012). The reason for this "preference" for the thyroid gland is not clear. Genetic factors, with the inheritance of common susceptibility loci for both MS and Graves' disease, may play a role as the prevalence of the latter condition was found to be increased in the family members of patients with MS (Broadley et al. 2000). Currently, the safety recommendation is to monitor thyroid function every 3 months for 48 months after the last alemtuzumab infusion and according to clinical judgment afterward (Table 2).

The first case of idiopathic thrombocytopenic purpura (ITP), an autoimmune condition against platelets, was identified in 2005. This index case died of intracranial hemorrhage, although he had phenomena of bleeding diathesis for 2 weeks before the fatal event, for which he had not sought medical attention (Coles et al. 2008). Subsequently, ITP was identified at a prevalence of $2.8 \%$ in CAMMS223 patients receiving alemtuzumab versus $0.9 \%$ on interferon $\beta$-1a. In CARE-MS1 and CARE-MS2, ITP was diagnosed in $0.8 \%$ and $0.84 \%$, respectively. Patient education on thrombocytopenia symptoms and monitoring with monthly blood counts (Table 2) have contributed to early detection and effective management (steroids, intravenous immunoglobulin, and/or rituximab) of all subsequent cases after the index case.

Seven cases of autoimmune renal disease have been reported in total to date, four of which were attributed to antiglomerular basement membrane disease (Goodpasture's syndrome without lung manifestations) and were thus more severe. Two of these four cases outside the sponsored trials eventually required renal transplant despite prompt treatment, but this was not the case for the two cases diagnosed in the phase 3 studies, who recovered with conservative treatment avoiding transplantation. The safety-monitoring program recommended in the summary of product characteristics is monthly urinalysis with microscopy (Table 2). Our view 
is that this is not helpful. First, our experience has been that Goodpasture's syndrome occurs too rapidly to be captured by routine testing. Second, many false positives are generated, leading to multiple repeats, irritation, and fatigue in both patients and monitoring staff.

Finally, there have been reported rare cases of sarcoidosis, as well as isolated cases of autoimmune cytopenias (neutropenia, hemolytic anemia, and pancytopenia), vitiligo, alopecia, and a few cases of pneumonitis.

\section{Pregnancy and Breastfeeding}

Alemtuzumab is not given during pregnancy, but the summary of product characteristics suggests it is safe to become pregnant 4 or more months after the last alemtuzumab infusion. This is particularly appealing for women of childbearing potential, as alemtuzumab is the only currently licensed treatment that remains effective long after being undetectable, therefore, offering disease control safely during early gestation (Jones and Coles 2014). However, patients should be monitored closely for thyroid disease during pregnancy after alemtuzumab (perhaps monthly); two cases of neonatal thyrotoxicosis have occurred in this context, requiring specialist help, both with good outcomes.

Alemtuzumab has been detected in the milk of lactating mice, but it is unknown whether this applies to human breast milk as well. Currently, women are advised to discontinue breastfeeding during alemtuzumab treatment and for 4 months following each course (Table 2).

\section{Long-Term Immunological Effects of Alemtuzumab}

Alemtuzumab induces a prolonged lymphopenia. B-cell counts return to the lower limits of normal $\left(\geq 0.1 \times 10^{9} / \mathrm{L}\right)$ within 7 months, $\mathrm{CD} 8^{+}$ cell counts $\left(\geq 0.2 \times 10^{9} / \mathrm{L}\right)$ within 20 months, and $\mathrm{CD}^{+}$cell counts $\left(\geq 0.4 \times 10^{9} / \mathrm{L}\right)$ within 35 months. T-cell counts rarely recover fully to their pretreatment levels though (Hill-Cawthorne et al. 2012). However, lymphopenia in absolute numbers does not seem to be the driving force behind alemtuzumab's efficacy and safety profile. The rate of lymphocyte count reconstitution was previously shown to be unrelated to either relapse risk (Kouzin-Ezewu et al. 2014), infection (Havrdova et al. 2013) or secondary autoimmunity (Jones et al. 2013). In addition, reconstitution of total numbers does not reflect the prolonged alteration in lymphocyte subgroups. For example, the B-cell pool after treatment is dominated by mature naïve cells $\left(\mathrm{CD} 19^{+} \mathrm{CD} 23^{+} \mathrm{CD} 27^{-}\right)$, whereas memory B cells $\left(\mathrm{CD} 19^{+} \mathrm{CD} 27^{+}\right)$are depleted. On the other hand, $\mathrm{T}$-cell repertoire is dominated by effector memory CD4 and CD8 populations for at least 9 months after treatment (Jones and Coles 2014).

The most challenging question is why alemtuzumab induces de novo autoimmune diseases in people whose original autoimmune disease (MS) is so well treated. The family of autoimmune disease induced by alemtuzumab are antibody mediated. But, B-cell populations and B-cell-activating factors do not correlate with secondary autoimmunity (Jones and Coles 2014). And B-cell-depletion therapy in MS does not seem to be associated with autoimmune phenomena either (Kappos et al. 2011). So, we hypothesize that changes within the T-cell compartment modify the B-cell response.

Autoimmunity associated with T-cell lymphopenia is a well-recognized phenomenon (Gleeson et al. 1996; King et al. 2004; Khoruts and Fraser 2005) and is believed to be a result of functional changes of $\mathrm{T}$ cells as they proliferate to "fill in the gap." This process is known as homeostatic proliferation and is driven by stimulation from T-cell receptor (TCR) self-peptide complexes, leading to production of oligoclonal $\mathrm{T}$-cell populations prone to autoreactivity (Kassiotis et al. 2003; Baccala and Theofilopoulos 2005; Khoruts and Fraser 2005). T-cell reconstitution after alemtuzumab is controlled primarily by homeostatic proliferation for at least 6 months posttreatment, leading to oligoclonal, highly proliferative $\left(\mathrm{Ki} 67^{+}\right)$, chronically activated $\left(\mathrm{CD} 28^{-} \mathrm{CD} 57^{+}\right)$memory-like $\mathrm{CD} 4^{+}$and $\mathrm{CD}^{+}\left(\mathrm{CCR}^{-} \mathrm{CD}^{-} 5 \mathrm{RA}^{-}\right.$or $\left.\mathrm{CCR}^{-} \mathrm{CD}^{-} 5 \mathrm{RA}^{+}\right)$ $\mathrm{T}$ cells (Jones et al. 2013). This response is more exaggerated (in contrast to new T-lymphocyte thymic production) in individuals who develop secondary autoimmunity (Jones et al. 2013). 
What alters the balance between homeostatic proliferation and thymopoesis is not fully understood. It could be influenced by several heterogeneous contributing factors like genetic background, exposure to external antigens, thymic reserve, and homeostatic cytokines. For example, baseline serum interleukin-21 levels were reportedly increased in patients who subsequently developed autoimmune side effects, possibly reflecting genetic alterations (Jones et al. 2009). However, commercial kits to detect interleukin-21 do not have the same predictive capacity and should not be used for pretreatment counseling (Azzopardi et al. 2014).

Apart from memory $\mathrm{T}$ cells, cells with a regulatory phenotype $\left(\mathrm{CD} 4{ }^{+} \mathrm{CD} 25^{\text {hi }} \mathrm{CD} 127^{\text {lo }}\right.$ CD45RA ${ }^{-}$FoxP $3{ }^{\text {hi }}$ ) are also expanded the first 6 months after alemtuzumab treatment (Cox et al. 2005). It is still not fully proven whether they function as a regulatory phenotype as well, or whether they are somewhat defective, to allow secondary autoimmunity in at least some patients. Another possibility is that T cells expanded through the homeostatic proliferation mechanism are endowed with enhanced abilities to escape regulation (Moxham et al. 2008).

Finally, it should be stressed that not every type of autoimmunity arising from lymphopenia after alemtuzumab is inadvertently "bad." We have speculated that disability improvement posttreatment may be, in part, a result of proremyelinating effects of the drug, mediated by neurotrophic factors produced by expanding autoreactive $\mathrm{T}$ cells. In the laboratory, peripheral blood mononuclear cell cultures, specifically stimulated by myelin basic protein (MBP), were shown to produce increased concentrations of brain-derived neurotrophic factor (BDNF), platelet-derived growth factor (PDGF), and ciliary neurotrophic factor (CNTF), which are factors with established properties of promoting neuronal and oligodendrocytic survival and differentiation (Jones et al. 2010). Media from such cultures promoted survival of rat neurones and increased axonal length in vitro, but these effects were partially blocked by BDNF and CNTF neutralizing antibodies. The same media were also able to promote oligodendrocyte precursor cell survival, maturation, and myelination. Although not proven, it is hypothesized that proliferating $\mathrm{T}$ cells, autoreactive to MBP, can transverse the blood-brain barrier and promote neurotrophic factor production through their "cross talk" with $\mathrm{MBP}$, thus contributing to neuronal repair and remyelination. This is a mechanism described previously as "neuroprotective autoimmunity" (Moalem et al. 2000).

\section{CLINICAL SCENARIOS OF ALEMTUZUMAB INEFFICACY}

Two patients have been reported whose multiple sclerosis disease activity seems to have worsened after alemtuzumab. They subsequently responded to rituximab, suggesting that their multiple sclerosis was always, or had been modified by alemtuzumab to be, driven predominantly by Bcell autoimmunity (Haghikia et al. 2014).

In one case of neuromyelitis optica, alemtuzumab treatment led to monocytic infiltration of the CNS, with fatal results (Gelfand et al. 2014). In three Cambridge cases of neuromyelitis optica, this effect was not seen, but alemtuzumab was not efficacious and indeed the disease may have been exacerbated (Azzopardi et al. 2016). Alemtuzumab was not an effective treatment of one person with Balo's concentric sclerosis (Brown et al. 2013).

\section{CONCLUDING REMARKS}

Three decades of experience have established the merits and concerns of alemtuzumab as a treatment of multiple sclerosis. In its favor, infrequent dosing leads to prolonged efficacy that it is not surpassed by any other licensed treatment. And there are robust clinical trial data to support its use as a first- or second-line treatment choice for relapsing remitting disease (although firstline use is not approved or reimbursed in all regions). But its safety profile is complex and requires monitoring for 4 years after each infusion. Unhelpfully, patients are most at risk of serious adverse events when their multiple sclerosis is most suppressed, and their disability has probably stabilized or improved. The ideal candidate for alemtuzumab then is someone with active disease who understands the "high-risk/ 
high-gain" value of alemtuzumab and who will comply with the safety-monitoring program long term. Conversely, alemtuzumab is not appropriate in someone with cognitive impairment without good support, or with erratic behavior, who may default from safety monitoring. Alemtuzumab is a useful option for women who require disease control during and after pregnancy. We would not recommend alemtuzumab in patients with rapid progression, where the distinction between relapsing remitting or progressive disease is unclear. For if alemtuzumab was used, and the person continued to deteriorate through progressive disease, they would have gained nothing, but would now be open to 4 years of monitoring and risk of serious adverse events.

Clearly there are some safety concerns with alemtuzumab, but its ability to transform the lives of at least some MS patients cannot be challenged. The scientific community looks forward to the day when highly effective immunotherapies with minimal side effects will be commercially available, but until then alemtuzumab remains a very reasonable choice for active disease. At some future point, when alemtuzumab is superseded, it might yet be that the development of this drug is valued for its historical demonstration of the benefits of treating multiple sclerosis early in the "window of therapeutic opportunity” (Coles et al. 2006).

\section{REFERENCES}

Azzopardi L, Thompson SAJ, Harding KE, Cossburn M, Robertson N, Compston A, Coles AJ, Jones JL. 2014 Predicting autoimmunity after alemtuzumab treatment of multiple sclerosis. J Neurol Neurosurg Psychiatry 85: 795798.

Azzopardi L, Cox AL, McCarthy CL, Jones JL, Coles AJ. 2016. Alemtuzumab use in neuromyelitis optica spectrum disorders: A brief case series. J Neurol 263: 25-29.

Baccala R, Theofilopoulos AN. 2005. The new paradigm of T-cell homeostatic proliferation-induced autoimmunity. Trends Immunol 26: 5-8.

Bandala-Sanchez E, Zhang Y, Reinwald S, Dromey JA, Lee BH, Qian J, Bohmer RM, Harrison LC. 2013. T cell regulation mediated by interaction of soluble CD52 with the inhibitory receptor Siglec-10. Nat Immunol 14: 741-748.

Berker D, Isik S, Ozuguz U, Tutuncu YA, Kucukler K, Akbaba G, Aydin Y, Guler S. 2011. Prevalence of incidental thyroid cancer and its ultrasonographic features in sub- centimeter thyroid nodules of patients with hyperthyroidism. Endocrine 39: 13-20.

Broadley SA, Deans J, Sawcer SJ, Clayton D, Compston DA. 2000. Autoimmune disease in first-degree relatives of patients with multiple sclerosis. A UK survey. Brain 123: 1102-1111.

Brown J, Coles A, Jones J. 2013. First use of alemtuzumab in Balo's concentric sclerosis: A case report. Mult Scler 19: 1673-1675.

Button T, Altmann D, Tozer D, Dalton C, Hunter K, Compston A, Coles A, Miller D. 2013. Magnetization transfer imaging in multiple sclerosis treated with alemtuzumab. Mult Scler 19: 241-244.

Cohen JA, Coles AJ, Arnold DL, Confavreux C, Fox EJ, Hartung HP, Havrdova E, Selmaj KW, Weiner HL, Fisher E, et al. 2012. Alemtuzumab versus interferon $\beta$-1a as first-line treatment for patients with relapsing-remitting multiple sclerosis: A randomised controlled phase 3 trial. Lancet 380: 1819-1828.

Coles AJ, Wing MG, Molyneux P, Paolillo A, Davie CM, Hale G, Miller D, Waldmann H, Compston A. 1999. Monoclonal antibody treatment exposes three mechanisms underlying the clinical course of multiple sclerosis. Ann Neurol 46: 296-304.

Coles AJ, Cox A, Le Page E, Jones J, Trip SA, Deans J, Seaman S, Miller DH, Hale G, Waldmann H, et al. 2006. The window of therapeutic opportunity in multiple sclerosis: Evidence from monoclonal antibody therapy. J Neurol 253: 98-108.

Coles AJ, Compston DA, Selmaj KW, Lake SL, Moran S, Margolin DH, Norris K, Tandon PK. 2008. Alemtuzumab vs. interferon $\beta$-1a in early multiple sclerosis. New Engl J Med 359: 1786-1801.

Coles AJ, Twyman CL, Arnold DL, Cohen JA, Confavreux C, Fox EJ, Hartung HP, Havrdova E, Selmaj KW, Weiner HL, et al. 2012a. Alemtuzumab for patients with relapsing multiple sclerosis after disease-modifying therapy: A randomised controlled phase 3 trial. Lancet 380: 18291839.

Coles AJ, Fox E, Vladic A, Gazda SK, Brinar V, Selmaj KW, Skoromets A, Stolyarov I, Bass A, Sullivan H, et al. 2012b. Alemtuzumab more effective than interferon $\beta$-1a at 5 year follow-up of CAMMS223 clinical trial. Neurology 78: 1069-1078.

Costelloe L, Jones J, Coles A. 2012. Secondary autoimmune diseases following alemtuzumab therapy for multiple sclerosis. Expert Rev Neurother 12: 335-341.

Cox AL, Thompson SA, Jones JL, Robertson VH, Hale G, Waldmann H, Compston DA, Coles AJ. 2005. Lymphocyte homeostasis following therapeutic lymphocyte depletion in multiple sclerosis. Eur J Immunol 35: 33323342 .

Frischer JM, Bramow S, Dal-Bianco A, Lucchinetti CF, Rauschka H, Schmidbauer M, Laursen H, Sorensen PS, Lassmann H. 2009. The relation between inflammation and neurodegeneration in multiple sclerosis brains. Brain 132: $1175-1189$.

Gelfand JM, Cotter J, Klingman J, Huang EJ, Cree BA. 2014. Massive CNS monocytic infiltration at autopsy in an alemtuzumab-treated patient with NMO. Neurol Neuroimmunol Neuroinflamm 1: e34. 
Gleeson PA, Toh BH, van DI. 1996. Organ-specific autoimmunity induced by lymphopenia. Immunol Rev 149: 97125.

Goodin DS, Frohman EM, Garmany GP Jr, Halper J, Likosky WH, Lublin FD, Silberberg DH, Stuart WH, van den Noort S. 2002. Disease modifying therapies in multiple sclerosis: Report of the Therapeutics and Technology Assessment Subcommittee of the American Academy of Neurology and the MS Council for Clinical Practice Guidelines. Neurology 58: 169-178.

Haghikia A, Dendrou CA, Schneider R, Grüter T, Postert T, Matzke M, Stephanik H, Fugger L, Gold R. 2014. Severe Bcell-mediated CNS disease secondary to alemtuzumab therapy. Lancet 16: 104-106.

Hale G, Dyer MJ, Clark MR, Phillips JM, Marcus R, Riechmann L, Winter G, Waldmann H. 1988. Remission in duction in non-Hodgkin lymphoma with reshaped human monoclonal antibody CAMPATH-1H. Lancet 2: 1394-1399.

Havrdova EDLA, Cohen JA, Coles AJ, Fox EJ, Hartung HP, Selmaj K, Weiner HL, Palmer J, Margolin DH, et al. 2013 Infection risk with alemtuzumab in patients with relapsing remitting multiple sclerosis: Pooled results from the CARE-MS I and CARE-MS II trials. Mult Scler 19: 74-78.

Hill-Cawthorne GA, Button T, Tuohy O, Jones JL, May K, Somerfield J, Green A, Giovannoni G, Compston DA, Fahey MT, et al. 2012. Long term lymphocyte reconstitution after alemtuzumab treatment of multiple sclerosis. $J$ Neurol Neurosurg Psychiatry 83: 298-304.

Hu Y, Turner MJ, Shields J, Gale MS, Hutto E, Roberts BL, Siders WM, Kaplan JM. 2009. Investigation of the mechanism of action of alemtuzumab in a human CD52 transgenic mouse model. Immunology 128: 260-270.

Jones JL, Coles AJ. 2014. Mode of action and clinical studies with alemtuzumab. Exp Neurol 262: 37-43.

Jones JL, Phuah CL, Cox AL, Thompson SA, Ban M, Shawcross J, Walton A, Sawcer SJ, Compston A, Coles AJ. 2009. IL-21 drives secondary autoimmunity in patients with multiple sclerosis, following therapeutic lymphocyte depletion with alemtuzumab (Campath-1H). J Clin Invest 119: 2052-2061.

Jones JL, Anderson JM, Phuah CL, Fox EJ, Selmaj K, Margolin D, Lake SL, Palmer J, Thompson SJ, Wilkins A, et al 2010. Improvement in disability after alemtuzumab treatment of multiple sclerosis is associated with neuroprotective autoimmunity. Brain 133: 2232-2247.

Jones JL, Thompson SA, Loh P, Davies JL, Tuohy OC, Curry AJ, Azzopardi L, Hill-Cawthorne G, Fahey MT, Compston A, et al. 2013. Human autoimmunity after lymphocyte depletion is caused by homeostatic T-cell proliferation. Proc Natl Acad Sci 110: 20200-20205.

Kappos L, Li D, Calabresi PA, O'Connor P, Bar-Or A, Barkhof F, Yin M, Leppert D, Glanzman R, Tinbergen J, et al. 2011. Ocrelizumab in relapsing-remitting multiple sclerosis: A phase 2, randomised, placebo-controlled, multicentre trial. Lancet 378: 1779-1787.

Kassiotis G, Zamoyska R, Stockinger B. 2003. Involvement of avidity for major histocompatibility complex in homeostasis of naïve and memory T cells. J Exp Med 197: 1007-1016.

Khoruts A, Fraser J. 2005. A causal link between lymphopenia and autoimmunity. Immunol Lett 98: 23-31.
King C, Ilic A, Koelsch K, Sarvetnick N. 2004. Homeostatic expansion of $\mathrm{T}$ cells during immune insufficiency generates autoimmunity. Cell 117: 265-277.

Kouzin-Ezewu O, Azzopardi L, Parker RA, Tuohy O, Compston A, Coles A, Jones J. 2014. Accelerated lymphocyte recovery after alemtuzumab does not predict multiple sclerosis activity. Neurology 82: 2158-2164.

Lockwood CM, Thiru S, Isaacs JD, Hale G, Waldmann H. 1993. Long-term remission of intractable systemic vasculitis with monoclonal antibody therapy. Lancet 341: 1620-1622.

McCarthy CL, Tuohy O, Compston DA, Kumararatne DS, Coles AJ, Jones JL. 2013. Immune competence after alemtuzumab treatment of multiple sclerosis. Neurology $\mathbf{8 1}$ : 872-876.

Moalem G, Gdalyahu A, Shani Y, Otten U, Lazarovici P, Cohen IR, Schwartz M. 2000. Production of neurotrophins by activated T cells: Implications for neuroprotective autoimmunity. J Autoimmun 15: 331-345.

Moreau T, Thorpe J, Miller D, Moseley I, Hale G, Waldmann H, Clayton D, Wing M, Scolding N, Compston A. 1994. Preliminary evidence from magnetic resonance imaging for reduction in disease activity after lymphocyte depletion in multiple sclerosis. Lancet 344: 298-301.

Moreau T, Coles A, Wing M, Isaacs J, Hale G, Waldmann H, Compston A. 1996. Transient increase in symptoms associated with cytokine release in patients with multiple sclerosis. Brain 119: 225-237.

Moxham VF, Karegli J, Phillips RE, Brown KL, Tapmeier TT, Hangartner R, Sacks SH, Wong W. 2008. Homeostatic proliferation of lymphocytes results in augmented memory-like function and accelerated allograft rejection. J Immunol 180: 3910-3918.

Rau D, Lang M, Harth A, Naumann M, Weber F, Tumani H, Bayas A. 2015. Listeria meningitis complicating alemtuzumab treatment in multiple sclerosis-Report of two cases. Int J Mol Sci 16: 14669-14676.

Tuohy O, Costelloe L, Hill-Cawthorne G, Bjornson I, Harding K, Robertson N, May K, Button T, Azzopardi L, Kouzin-Ezewu O, et al. 2015. Alemtuzumab treatment of multiple sclerosis: Long-term safety and efficacy. J Neurol Neurosurg Psychiatry 86: 208-215.

Vavasour I, MacKay A, Li D, Laule C, Traboulsee A. 2015. Advanced imaging in lesion and normal-appearing white matter over 2 years in MS patients treated with alemtuzumab (S29.009). Neurology 84 (14 Suppl).

Waldmann H, Hale G. 2005. CAMPATH: from concept to clinic. Philos Trans R Soc Lond B Biol Sci 360: 1707-1711.

Waldmann H, Polliak A, Hale G, Or R, Cividalli G, Weiss L, Weshler Z, Samuel S, Manor D, Rachmilewitz EA, et al. 1984. Elimination of graft-versus-host disease by in-vitro depletion of alloreactive lymphocytes with a monoclonal rat anti-human lymphocyte antibody (CAMPATH-1). Lancet 2: 483-486.

Wing MG, Moreau T, Greenwood J, Smith RM, Hale G, Isaacs J, Waldmann $\mathrm{H}$, Lachmann PJ, Compston A. 1996. Mechanism of first-dose cytokine-release syndrome by CAMPATH 1-H: Involvement of CD16 (FcrRIII) and CD11a/CD18 (LFA-1) on NK cells. J Clin Invest 98: 28192826. 


\section{$\$ \mathrm{CSH} \&$ Cold Spring Harbor

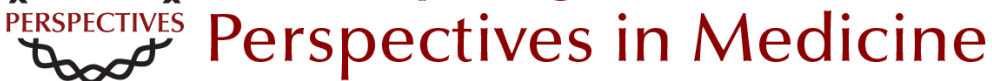

\section{Alemtuzumab as Treatment for Multiple Sclerosis}

Serafeim Katsavos and Alasdair Coles

Cold Spring Harb Perspect Med 2018; doi: 10.1101/cshperspect.a032029 originally published online March 2, 2018

\section{Subject Collection Multiple Sclerosis}

Multiple Sclerosis Pathology

Hans Lassmann

Regulatory T Cells: From Discovery to

Autoimmunity

Alexandra Kitz, Emily Singer and David Hafler

The Multiple Roles of B Cells in Multiple Sclerosis

and Their Implications in Multiple Sclerosis

Therapies

Rui Li and Amit Bar-Or

Autologous Hematopoietic Stem Cell

Transplantation in the Treatment of Multiple

Sclerosis

Carolina A. Rush, Harold L. Atkins and Mark S.

Freedman

B-Cell Therapies in Multiple Sclerosis

Joseph J. Sabatino, Jr., Scott S. Zamvil and Stephen L. Hauser

Oral Therapies for Multiple Sclerosis Simon Faissner and Ralf Gold

Interferon $\beta$ for Multiple Sclerosis

Dejan Jakimovski, Channa Kolb, Murali

Ramanathan, et al.

Alemtuzumab as Treatment for Multiple Sclerosis Serafeim Katsavos and Alasdair Coles
Natalizumab: Perspectives from the Bench to

Bedside

Afsaneh Shirani and Olaf Stüve

Daclizumab Therapy for Multiple Sclerosis Bibiana Bielekova

Lifestyle and Environmental Factors in Multiple

Sclerosis

Lars Alfredsson and Tomas Olsson

Biomarkers in Multiple Sclerosis

Anu Paul, Manuel Comabella and Roopali Gandhi

The Evolving Mechanisms of Action of Glatiramer

Acetate

Thomas Prod'homme and Scott S. Zamvil

Regulation of Astrocyte Functions in Multiple Sclerosis

Michael A. Wheeler and Francisco J. Quintana

Experimental Autoimmune Encephalomyelitis

(EAE) as Animal Models of Multiple Sclerosis (MS)

Simon Glatigny and Estelle Bettelli

Neurodegeneration in Progressive Multiple

Sclerosis

Graham Campbell and Don Mahad

For additional articles in this collection, see http://perspectivesinmedicine.cshlp.org/cgi/collection/ 